\title{
Castration-Resistant Prostate Cancer: Mechanisms, Targets, and Treatment
}

\author{
Teresa Maria Santos Amaral, Daniela Macedo, Isabel Fernandes, and Luis Costa \\ Oncology Division, Hospital de Santa Maria, Instituto de Medicina Molecular, 1649-039 Lisbon, , Portugal \\ Correspondence should be addressed to Luis Costa, luiscosta.oncology@gmail.com
}

Received 26 September 2011; Revised 1 December 2011; Accepted 20 December 2011

Academic Editor: William L. Dahut

Copyright (C 2012 Teresa Maria Santos Amaral et al. This is an open access article distributed under the Creative Commons Attribution License, which permits unrestricted use, distribution, and reproduction in any medium, provided the original work is properly cited.

\begin{abstract}
Patients with castration-resistant prostate cancer (CRPC), who progress after docetaxel therapy, had until very recently, only a few therapeutic options. Recent advances in this field brought about new perspectives in the treatment of this disease. Molecular, basic, and translational research has given us a better understanding on the mechanisms of CRPC. This great investment has turned into a more rational approach to the development of new drugs. Some of the new treatments are already available to our patients outside clinical trials and may include inhibitors of androgen biosynthesis; new chemotherapy agents; bone-targeted therapy; and immunotherapy. This paper aims to review the mechanisms of prostate cancer resistance, possible therapeutic targets, as well as new options to treat CRPC.
\end{abstract}

\section{Introduction}

Prostate cancer is the most common malignancy in males in Western countries, representing the second leading cause of cancer death [1]. Advances in screening and diagnosis have allowed detection of the disease in early stages (approximately $85 \%$ of cases diagnosed), stages at which the therapeutic options are curative and include surgery, radiation and, in some cases, active surveillance only [2-4]. However, for late-stage disseminated disease, current therapies are merely palliative. In 1941, a study of Huggins and Hodges showed the close relationship of androgens with prostate tumor growth and androgen-deprivation therapy (castration) became the key treatment for these stages in monotherapy or in combination with other methods $[2,4$, 5]. Initial responses to castration therapy are quite favorable, with a significant clinical regression and rapid biochemical responses, as assessed by decline in levels of serum marker, prostate-specific antigen (PSA) in $80-90 \%$ of patients with metastatic disease $[2,4,6]$. Despite a good initial response, remissions last on average 2-3 years, with eventual progression occurring despite castration $[4,5,7]$. In these cases prostate cancer will progress to a castration-insensitive phase of disease (Castration-Resistant Prostate Cancer-CRPC) which carries a worse prognosis and translates into a survival time of 16-18 months in average from the beginning of progression [2, 4-6]. Systemic therapies have also been an option in the management to these patients. However, chemotherapy is not well tolerated by all CRPC patients, who were often elderly men with limited bone marrow reserve and concurrent medical conditions [8]. In 2004 the result of two major phase 3 clinical trials established docetaxel as the first-line chemotherapy regimen in advanced stage disease [6].

Treatment of patients with CRPC remains a significant clinical challenge. This paper aims to address the mechanisms of resistance in the context of CRPC, as well as new therapeutic targets, and a brief discussion of current and future treatments.

\section{Mechanisms and Targets in CRPC}

The key for the development of new drugs and to optimize androgenic suppression in advanced stages of CRPC is the identification and characterization of molecular targets and mechanisms that lead to tumor growth. Disease progression involves the development of cellular adaptive pathways of 
survival in an androgen-depleted environment [3]. Experimental evidence assigns an important role to the continuous activation of the androgenic receptors (ARs) in tumor growth, as well as alternative independent routes [2]. In general, resistance mechanisms can be divided into 6 groups.

(i) Increased Expression of Enzymes Involved in Steroidogenesis. Studies have suggested that, in CRPC patients, even castrate serum levels of androgen are still sufficient for AR activation and able to maintain cancer cells survival. Indeed, the intratumoral levels of testosterone in CRPC patients are equal of those found in noncastrate patients [4]. The source of these androgens is thought to be derived from the synthesis of androgens directly in prostate cancer cells due to an upregulation of the enzymes and activation of the routes necessary for the synthesis of androgens such as testosterone and dihydrotestosterone $[3,5,9]$. Also bone metastases contain intact enzyme pathways for conversion of adrenal androgens to testosterone and dihydrotestosterone [4]. Montgomery and colleagues showed that there was marked reversal of the DHT:testosterone ratio in the metastatic tumor. These tumor cells express significantly lower levels of SRD5A2, which catalyses the conversion of testosterone to DHT, and higher levels of UGT2B15 and UGT2B17, which mediate the irreversible glucuronidation of DHT metabolites. Marked up regulation of CYP19A1, which mediates the aromatization of testosterone to estradiol, was also observed in the metastases samples [3-5, 9].

(ii) Increased Expression of $A R$. The overexpression of AR have been involved in the progression of prostate cancer [3]. The activated AR pathways observed in these CRPC patients has been postulated as a result of genetic phenomena that promotes increased sensitivity of AR. DNA amplifications are responsible for AR overexpression and for its activation in presence of low levels of ligand (androgens) [3,9].

(iii) AR Gene Mutations and Altered Ligand Specificity. While the androgens are the main factors of tumor growth and AR signaling, the presence of AR mutations leads to its activation by nonandrogenic steroid molecules and antiandrogens [3]. The majority AR mutations are point mutations in the AR ligand-binding domain, and initially this was considered relevant to explain why $10-30 \%$ of patients receiving antiandrogens treatment experience paradoxical PSA drop on cessation of treatment [5]. However the AR mutations could occur in other regions such as the amino terminus or the DNA binding domain that confer oncogenic properties to the AR [5]. At the present, the role of AR mutations in the antiandrogen withdrawal phenomena is called into questioned and a new explanation is offered since the discovery of alternative splicing of the AR. In fact, in recent reports $[6,7]$ it was shown that splice variants of AR with deletion of exons 5,6 , and 7 could result in AR capable to translocate to the nucleus without ligand binding.

(iv) Downstream Signaling Receptor for Androgens. One of the most important mechanisms in the development of castration resistance is the activation of different signal transduction pathways in CRPC cells. They could enhance the activity of the AR or its coactivators in the presence of low levels or even in the absence of androgen. These include other receptors such as epithelial growth factors, insulin growth factors, and tyrosine-kinase receptor [7].

(v) Bypass Pathways. The induction of bypass pathways independent of $\mathrm{AR}$, is an important mechanism of castration resistance, that can overcame apoptosis induced by androgen-deprivation therapy. One such example of this is the up-regulation of antiapoptotic proteins, including the protein $\mathrm{Bcl}-2$ gene $[3,10]$.

(vi) Stem Cells. Prostatic cancer stem cells are rare and undifferentiated cells that do not express AR on their surface, being independent of androgens to survive [3]. Currently it is thought that these cells can be responsible for maintaining tumor growth and development, because they are able to survive under androgen-deprivation therapy. The identification of these cells is possible based on the expression of surface protein ( $\alpha 1 \beta 1$ integrin and CD133), which could allow new targets therapies [3].

\section{Treatment Options}

The growth of prostate cancer is originally androgen dependent and metastatic tumors are generally treated with androgen ablation therapy, with or without antiandrogen supplementation $[2,11,12]$. However, resistance to hormonal therapy occurs within 12-18 months (remissions last on average 2-3 years, progression occurs even under castration $[4,5,9])$, referred to as hormone-refractory or CRPC [2]. Resistance to hormones (in patients with metastatic disease) is probably shorter than 2-3 years, using PSA. In addition survival with CRPC is now longer than 16-18 months. Until recently, patients with castration-resistant prostate cancer had limited treatment options after docetaxel chemotherapy. However, in 2010, new options emerged [8]. The three nonhormonal systemic approaches that have been found to prolong survival are docetaxel as first line [13] chemotherapy, cabazitaxel as second-line cytotoxic chemotherapy $[8$, 14], and a vaccine named sipuleucel-T [15]. A new hormonal manipulation with abiraterone acetate [14] also showed to prolong survival in CRPC.

The current palliative treatment options for patients with CRPC can be divided in different groups such as secondary hormonal therapies, chemotherapy agents, vaccine-based immune therapy, bisphosphonates, radiotherapy and novel targets.

3.1. Hormonal Therapies. Drugs that reduce circulating levels of androgens or that competitively inhibit the action of androgens remain central to the treatment of prostate cancer. The surgical or medical castration with orchiectomy or gonadotropin-releasing hormone $(\mathrm{GnRH})$ agonists, respectively, suppresses testicular testosterone generation. However, the duration of response to castration is short 
(12-33 months) and, in almost all patients, is followed by the emergence of a castration-resistant phenotype [3]. The combination with antiandrogens to achieve the maximum androgen blockade (MAB) did not prove to prolong survival and $30 \%$ of the patients have a drop in PSA after discontinuing antiandrogens $[3,16]$. Maintenance of oral glucocorticoids at lower doses $(10 \mathrm{mg} /$ day $)$ can result in temporary PSA responses for $25 \%$ of the patients, presumably due to adrenal androgen suppression $[3,17]$.

For patients whose disease progresses after a MAB, antiandrogen can be discontinued [18] or can be switched to an alternative antiandrogen as showed in several reports [1820].

High-dose (150 mg daily) bicalutamide as second-line hormonal therapy resulted in $\geq 50 \%$ PSA reduction in $20 \%$ $45 \%$ of patients $[18,21-23]$.

Diethylstilboestrol (DES), a synthetic estrogen, as well as the other estrogens, suppresses the hypothalamic-pituitarygonadal axis and it reduces $\geq 50 \%$ the total PSA in $26 \%$ to $66 \%$ of patients with CRPC. However, the thromboembolic toxicity limited is use $[18,24,25]$.

Ketoconazol is an antifungal agent that can be given to CRPC patients after antiandrogen withdrawal because it inhibits cytochrome P-450 enzyme-mediated steroidogenesis in testes and adrenal glands and when given at high-dose $(1200 \mathrm{mg} /$ day $)$ or low dose $(600 \mathrm{mg} /$ day) it resulted in $\geq 50 \%$ PSA reduction in $27 \%$ to $63 \%$ and 27 to $46 \%$, of patients, respectively [18].

Abiraterone acetate, a prodrug of abiraterone, is potent and highly selective inhibitor of androgen biosynthesis that blocks cytochrome P450 c17 (CYP 17), a critical enzyme in testosterone synthesis, thereby blocking androgen synthesis by the adrenal glands and testes and within prostate tumor [26-30]. The Cou-AA-301 trial compared abiraterone acetate (1000 mg once daily) plus prednisone versus placebo plus prednisone in patients who had previously received docetaxel. This study randomly assigned 1195 patients and the results exceeded the preplanned criteria, with an overall survival longer in the abiraterone arm (14.8 months versus 10.9 months $)(P<0.0001)$ and with all secondary end points favoring the treatment group, including time to PSA progression (10.2 versus 6.6 months $)(P<0.001)$, progression-free survival (5.6 months versus 3.6 months) $(P<0.001)$, and PSA response rate $(29 \%$ versus $6 \%)$ $(P<0.001)[26]$. The adverse events more frequently related to abiraterone acetate than to placebo group were urinary tract infections, adverse events associated with elevated mineralocorticoid levels such as fluid retention and edema, hypokalemia, and hypertension, as well as cardiac disorders and liver-function test abnormalities [26].

MDV3100 is an androgen receptor antagonist which prevents nuclear translocation and recruitment of coactivators; it has been shown antitumor activity in men with CRPC after failure of prior hormonal therapy, in phase I/II trial $[31,32]$. The AFFIRM trial (a phase III trial) compared MDV3100 versus placebo in patients with docetaxel-refractory CRPC. $[18,33-35]$. A planned interim analysis of the AFFIRM trial revealed that estimated median survival was 18.4 months for men treated with MDV3100, compared with 13.6 months for men treated with placebo $(P<0.0001)$. This translates into a $37 \%$ reduction in the risk for death with MDV3100 (hazard ratio, 0.631). As a result, the trial's Independent Data Monitoring Committee recommended that AFFIRM should be stopped earlier and that men who were receiving placebo should be offered MDV3100. The recommendation was based on the fact that the study's prespecified interim efficacy stopping criteria were successfully met. The committee also examined the safety profile to date and determined that MDV3100 demonstrated a risk/benefit ratio that was favorable enough to stop the study.

The PREVAIL trial (A safety and efficacy study of oral MDV3100 in chemotherapy-naïve patients with progressive metastatic prostate cancer) is still ongoing and recruiting patients.

\subsection{Bone-Targeted Therapy: Bisphosphonates and Denosumab.} In men with advanced prostate cancer, the biphosphonate zoledronate has been shown to prevent or delay skeletal complications in men with bone metastases, as well as to palliate bone pain $[36,37]$. At an average followup of 24 months, there was a significant reduction in the frequency of skeletal related events (SREs) in men receiving zoledronic acid compared to placebo (38 versus 49 percent), and the median time to develop an SRE was significantly longer with zoledronic acid (488 versus 321 days) [38]. Biphosphonates may also have a role in preventing osteopenia that frequently accompanies the use of androgen-deprivation therapy [39$41]$.

More recent data have show that denosumab is also an effective treatment for patients with CRPC and bone metastases. In a phase III study denosumab, a human monoclonal antibody against RANKL, was compared with zoledronic acid for prevention of skeletal-related events. The results showed advantage to denosumab, representing another treatment opportunity for CRPC patients [42].

\subsection{External Beam Radiotherapy, Hemibody RT, and Ra-} dioisotope Pharmaceuticals. Focal external beam radiation therapy (RT) is a palliative treatment possibility that should be considered for men with CRPC and bone pain that is limited to one or a few sites. Several clinical trials as well as a systematic review of the literature suggest that single treatments with fractionation schedules provide palliation with cost effectiveness and patient convenience [43-46].

Hemibody RT could also be considered in selected patients with symptomatic disease limited to one side of the diaphragm, in order to rapid pain relief, when multiple bone metastases are present [47].

However, this technique has frequently been replaced by the administration of radioisotope pharmaceuticals which may be associated with less toxicity and are more appropriated for patients with multiple painful lesions [48].

In order for these patients to be treated with radioisotopes the presence of uptake on bone scan due to metastatic disease at sites that correlate with pain is necessary. These radioisotopes are used in men with advanced prostate cancer with osteoblastic bone metastasis. These patients are often characterized by a high ratio of bone to soft tissue metastases. 
Multiple radioisotopes have been used but the most extensive data are with 89-strontium (89Sr), Radium-223 and 153-samarium (153Sm). Several clinical trials provide the rational for the use of this approach in carefully selected patients [49-55].

Radium-223 is an alpha-emitting pharmaceutical agent that showed to improve survival in a phase III study [56]. Compared with placebo, Radium-223 was associated with improved overall survival (median 14.0 versus 11.2 months; HR, $0.69 ; P=.002$ )

3.4. Chemotherapy. Docetaxel is the only approved chemotherapy that has been shown to prolong survival among men with metastatic CRPC. The trial TAX 327 compared chemotherapy with docetaxel plus prednisone versus mitoxantrone plus prednisone with a $24 \%$ relative reduction for men with metastatic CRPC and a significant survival benefit $(P=0.009)$ in the docetaxel arm $[11,30]$. Docetaxel was also effective in pain reduction (35\% versus $22 \%)(P=0.001)$ $[11,30]$. In SWOG 9916 trial, docetaxel plus estramustine was compared with mitoxantrone plus prednisone and the docetaxel regimen also conferred a significant survival benefit ( $\mathrm{HR}$ for death $0.80 ; 95 \% \mathrm{CI}=0.67-0.97$ ) and increased median survival (17.5 versus 15.6 months) $(P=$ $0.02)$ over the mitoxantrone arm $[32,57]$.

Several docetaxel combinations have been evaluated in phase 2 studies for CRPC, including associations with tyrosine kinase inhibitors, antiangiogenesis agents, and immunologic agents [32, 58]. Phase III trials, combining docetaxel with other chemotherapy agents, did not demonstrate superiority to docetaxel plus prednisone [31].

Epothilones, namely, ixabepilone and patupilone, have shown significant activity in men with CRPC [31, 59-62]. These molecules were evaluated in second-line chemotherapy in two phase II trials after progression with prior taxane $[63,64]$. Phase III trials with ixabepilone are in development and a phase II trial of patupilone is currently underway [31].

Eribulin mesylate (E7389) is a synthetic analog of the marine macrolide halichondrin $\mathrm{B}$, which acts as a novel microtubule modulator with a distinct mechanism of action (different from taxanes) $[31,63]$. An open-label, multicenter, single-arm, phase II study was conducted in patients with CRPC stratified by prior taxane therapy [31, 65]. Primary efficacy endpoint was PSA response rate defined as two consecutive $\geq 50 \%$ decreases in PSA levels from baseline. The secondary endpoints were duration of PSA response rate and objective response rate by RECIST criteria. One hundred and eight patients were available for analyses. Of these 50 were taxane pretreated. Eribulin showed activity in patients with metastatic CRPR, especially in those with taxane naïve disease. Side effects, mainly hematological toxicity (grade 3 and 4 leucopenia and neutropenia), fatigue, and peripheral neuropathy were manageable [66].

Satraplatin (JM-216) is an oral third-generation platinum compound evaluated in the SPARC trial in combination with prednisone in second-line therapy after docetaxel $[3,18]$. In this trial, satraplatin plus prednisone resulted in significant improvement in PFS (11.1 weeks versus 9.7 weeks $)(P<0.001)$ but there were no improvement in median overall survival compared with prednisone alone (61.3 weeks versus 61.4 weeks) $(P=0.80)$.

Cabazitaxel, a novel tubulin-binding taxane, is the first chemotherapy shown to improve survival in patients with docetaxel-refractory metastatic castration resistant prostatic cancer. In the TROPIC trial, a randomized phase III study compared cabazitaxel plus prednisone versus mitoxantrone plus prednisolone, in patients with docetaxel-refractory prostate cancer. The cabazitaxel arm showed an improvement in median PFS (2.8 months versus 1.4 months) $(P<$ 0.0001), median OS (15.1 months versus 12.7 months), and lower risk of death (hazard ratio 0.70$)(P<0.0001)$ $[8,14,66]$.

3.5. Vaccines-Based Immunotherapy. Sipuleucel-T (Provenge, APC8015) is an autologous dendritic cell vaccine, consisting of autologous peripheral blood mononuclear cells (PBMCs), including antigen-presenting cells (APCs), that have been activated ex vivo with a recombinant fusion protein (PA2024) composed of prostatic acid phosphatase (PAP) linked to granulocyte-macrophage colony-stimulating factor (GMCSF) [15]. In the first two randomized trials, sipuleucel$\mathrm{T}$, the primary endpoint was not accomplished since these studies did not show a significant effect on the time to disease progression comparing with placebo. Despite this, the hazard ratios were in favor of sipuleucel- $T[67,68]$. The subsequent IMPACT trial, a phase III, randomized trial, in patients with asymptomatic or minimally symptomatic metastatic CRPC, designed overall survival as the primary end point. This study resulted in a 4.1-month improvement in median overall survival and an improvement in the rate of 3-year survival (31\% versus $23 \%$ ) in sipuleucel-T arm, with limited toxicity. However, no significant effect on the time to objective disease progression was observed [15].

GVAX (CGI940/CG8711) is a cellular vaccine composed of two allogeneic prostate cancer cell lines (LNCaP and PC-3) that is genetically modified to secrete GM-CSF [17]. This vaccine showed clinical benefit with limited toxicity in phase I and II trials $[18,69,70]$. However, the two phase III trials (VITAL-1 and VITAL-2) evaluated GVAX against docetaxel plus prednisone in naïve CRPC and both were closed prematurely $[18,31]$. The VITAL- 1 study was closed when the unplanned futility analysis revealed a $<30 \%$ chance of meeting its predefined primary endpoint of OS improvement and the VITAL-2 terminated when an interim analysis revealed more deaths in the GVAX arm than in the control [18, 31, 33, 71].

PROSTVAC-VF is a cancer vaccine consisting of a recombinant vaccinia vector as a priming immunization with subsequent multiple booster vaccinations, using a recombinant fowlpox vector. This agent presented in the context of 3 costimulatory molecules (ICAM-1, BLA-7, and LFA-3) which, when taken together, demonstrate an increase in strength of the target immunologic response [31]. This vaccine was evaluated in phase I and II trials. The phase I trial showed PSA stabilization in $40 \%$ of patients and limited toxicity and, in the phase II study, patients in the PROSTVAC-VF arm achieved an 8.5-month improvement in median OS (25.1 months versus 16.6 months) and a $44 \%$ reduction in the 
death rate (Hazard ratio $0.56, P=0.0061$ ) $[72,73]$. Phase III trial are being planned and other vaccines are under current development [74].

\section{Other Targets}

The Endothelins (ETs) constitute a family of three 21-aminoacid peptides (ET-1, ET-2, and ET-3) that are synthesized as propeptides and are transformed to their active forms by sequential endopeptidase and ET-converting enzymemediated cleavage [79]. ETs are regulators of cell proliferation, vasomotor tone, and angiogenesis [31]. The ETs bind to two receptors, endothelin-A (ET-A) and endothelin-B (ET$\mathrm{B})$, and play an important role in angiogenesis, proliferation, escape from apoptosis, invasion, tumor growth, new bone formation, and bone metastasis $[31,74]$. ET and their receptors have emerged as a potential targets in CRPC $[74,79]$. Efficacy and safety of ET-A receptor blockadeatrasentan (ABT-627) - have been evaluated in a doubleblind, randomized, placebo-controlled, phase II trial [79]. Two hundred and eighty-eight asymptomatic patients were randomized to one of three study groups: placebo, $2.5 \mathrm{mg}$ atrasentan, $10 \mathrm{mg}$ atrasentan. Primary endpoint was time to progression. Secondary end points were time to PSA progression, bone scan changes, and changes in bone and tumor markers. Target therapy with atrasentan was well tolerated and results showed a potential to delay progression of CRPC.

Based on these results other phase III studies also evaluated atrasentan. In one of these studies [75] atrasentan did not reduce the risk of disease progression relative to placebo. However exploratory analyses showed that alkaline phosphatase and PSA levels were significantly lower in the treatment arm [31]. Another phase III study (SWOG S0421) tested atrasentan combined with docetaxel/prednisone in metastatic CRPC as a first-line therapy [80]. SWOG trial S0421 closed earlier based on interim finding that atrasentan added to docetaxel and prednisone did not confer additional survival benefit to patients with hormone-refractory prostate cancer.

The Data and Safety Monitoring Committee has determined that patients in phase III S0421 receiving atrasentan in addition to a standard chemotherapy regimen for advanced prostate cancer did not have longer survival or longer progression-free survival. Zibotentan (ZD 4054) is another ET-A receptor antagonist, which showed evidence of activity in a randomized phase II trial in men with castrateresistant prostate cancer and bone metastases [81]. Following these results two phase III trials $[82,83]$ were conducted. ENTHUSE M0 was discontinued following the results of an early efficacy review by the Independent Data Monitoring Committee. The company has concluded that zibotentan was unlikely to meet its primary efficacy endpoints progression free survival and overall survival. Results from ENTHUSE M1C are still awaited.

Angiogenesis inhibitors such as thalidomide and bevacizumab alone or in combination with docetaxel were studied in phase II trials with promising results. Thalidomide plus docetaxel versus docetaxel monotherapy, in a phase II trial in patients with metastatic CRPC, showed a $\geq 50 \%$ PSA decrease (53\% versus 37\%) $(P=0.32)$ and improvement in median overall survival (28.9 months versus 14.7 months) $(P=0.11)$ for patients in the thalidomide group $[18,84]$.

Bevacizumab, a recombinant humanized monoclonal antibody anti-VEGF, was studied in a phase II, in patients with docetaxel-refractory CRPC. Bevacizumab plus docetaxel resulted in $\geq 50 \%$ PSA reduction in $55 \%$ of patients, $37.5 \%$ partial responses, and a median overall survival of 9 months [85]. Bevacizumab, docetaxel and estramustine resulted in $>50 \%$ PSA reduction in $75 \%$ patients partial response in $59 \%$ of patients and median overall survival of 24 months [86]. However, phase III, CALGB 90401 trial did not show improvement in OS (22.6 months versus 21.5) with the addition of bevacizumab to docetaxel $[18,76]$.

The combination of docetaxel, thalidomide, bevacizum$\mathrm{ab}$, and prednisolone was also evaluated in a phase II trial with a $\geq 50 \%$ PSA reduction in $89.6 \%$ of patients. The median time to progression was 18.3 months and the median overall survival was 28.2 months [87]. More studies are needed before prescribing angiogenesis inhibitors outside clinical trials.

Src inhibitors, such as dasatinib, are being studied for prostate cancer because Src signaling is involved in androgen-induced proliferation. In a phase II trial in chemotherapy-naïve patients with metastatic CRPC, dasatinib ( $100 \mathrm{mg}$ orally twice daily) showed lack of progression in $43 \%$ of patients at week 12 and in $19 \%$ in patients at week 24 . It also revealed a decrease in the markers of bone metabolism (N-telopeptide and bone alkaline phosphatase) [31]. A randomized phase III trial with dasatinib plus docetaxel is ongoing [88].

Blockade of the T-cell inhibitory receptor CTL-associated antigen-4 (CTLA-4) augments and prolongs T-cell responses and is a strategy to elicit antitumor immunity [89]. Ipilimumab, an anti-CTLA-4 antibody, was tested in order to potentiate endogenous antitumor immunity to prostate cancer through combination immunotherapy with CTLA4 blockade and GM-CSF [90]. The results showed that this combination immunotherapy can induce the expansion not only of activated effector CD8 $\mathrm{T}$ cells in vivo but also of $\mathrm{T}$ cells that are specific for known tumor-associated antigens from endogenous immune repertoire.

In a pilot trial of CTLA-4 blockade with ipilimumab patients with CRPC were given a single dose of $3 \mathrm{mg} / \mathrm{kg}$ [89]. Results showed that this approach was safe and did not result in significant clinical autoimmunity. PSA modulating effects presented need further investigation in order to be fully understood.

Two phase III trials are now recruiting patients in order to compare ipilimumab with placebo [88]. One trial [91] will evaluate this approach in patients with metastatic disease, with at least one bone metastasis, prior treatment with docetaxel, and castrate levels of serum testosterone. The other trial [77] will include patients with metastatic castration-resistant prostate cancer who are asymptomatic or minimally symptomatic and who have not received prior chemotherapy or immunotherapy. 
TABLE 1: Summary of the therapeutic impact of new drugs in CRPC treatment.

\begin{tabular}{|c|c|c|c|c|}
\hline & $\begin{array}{l}\text { Reference, study phase, and } \\
\text { patient number }\end{array}$ & Efficacy results $\mathrm{PFS}^{*}, \mathrm{OS}^{+}$ & Comparator & PSA levels/PSA RR ${ }^{\#}$ \\
\hline Docetaxel & $\begin{array}{l}\text { Tannock et al. [13] } \\
\text { Phase III; } 1006 \text { pts }\end{array}$ & $\begin{array}{l}\text { Prolongation of median survival, } \\
\text { decrease in serum PSA level, predefined } \\
\text { reductions in pain and improvements of } \\
\text { quality of life }\end{array}$ & Mitoxantrone & Reduced \\
\hline Cabazitaxel & $\begin{array}{l}\text { Bono et al. [65] } \\
\text { Phase III; } 755 \text { pts }\end{array}$ & $\begin{array}{c}\text { Improved OS (95\% CI: } 0.59-0.83 \\
P<0.0001) \text { and median PFS (HR: } 0 \cdot 74 \\
0.64-0.86, P<0.0001)\end{array}$ & Mitoxantrone & Reduced \\
\hline Abiraterone acetate & $\begin{array}{l}\text { De Bono et al. [26] } \\
\text { Phase III; } 1195 \text { pts }\end{array}$ & $\begin{array}{c}\text { Prolongation of OS, time to PSA } \\
\text { progression }(10.2 \text { versus } 6.6 \text { months; } \\
P<0.001) \text {, progression-free survival }(5.6 \\
\text { months versus } 3.6 \text { months; } P<0.001) \\
\text { and PSA response rate }(29 \% \text { versus } 6 \% \text {, } \\
P<0.001)\end{array}$ & Placebo & Reduced (>29\%) \\
\hline \multirow[b]{2}{*}{ Bicalutamide } & $\begin{array}{l}\text { Kucuk et al. [22] } \\
\text { Phase II; } 52 \text { pts }\end{array}$ & $\begin{array}{c}\text { Decreases pain and improves symptom } \\
\text { status }\end{array}$ & Baseline after 1st line & $\begin{array}{c}\text { Reduced }(\geq 50 \% \text { in } \\
20 \% \text { pts })\end{array}$ \\
\hline & $\begin{array}{l}\text { Lodde et al. [23] } \\
\text { Prospective trial; } \\
38 \text { pts }\end{array}$ & PSA response rate & $\begin{array}{l}\text { Baseline after } \\
\text { antiandrogen } \\
\text { manipulation }\end{array}$ & Reduced ( $44.7 \%$ pts) \\
\hline DES & $\begin{array}{l}\text { Smith et al. [25] } \\
\text { Phase II; } 21 \text { pts }\end{array}$ & PSA response rate & $\begin{array}{c}\text { Baseline after 1st line } \\
\text { hormonal therapy }\end{array}$ & Reduced (43\% RR) \\
\hline Sipuleucel-T & $\begin{array}{l}\text { Kantoff et al. [15] } \\
\text { Phase III, } 512 \text { pts }\end{array}$ & $\begin{array}{l}\text { Relative reduction of } 22 \% \text { in the risk of } \\
\text { death as compared with the placebo } \\
\text { group (hazard ratio, } 0.78 ; 95 \% \\
\text { confidence interval (CI), } 0.61 \text { to } 0.98 \text {; } \\
\qquad P=0.03 \text { ) }\end{array}$ & Placebo & $\begin{array}{c}\text { Reduced }(\geq 50 \% \text { in } \\
2.6 \%)\end{array}$ \\
\hline MDV3100 & $\begin{array}{c}\text { Scher et al. [34] } \\
\text { Phase I-II } \\
\text { Phase III results } \\
\text { not available }\end{array}$ & NA & NA & NA \\
\hline Patupilone & $\begin{array}{c}\text { Beardsley et al. [63] Phase } \\
\text { II, } 83 \text { pts }\end{array}$ & $\begin{array}{c}\text { Prolongation of PFS, PSA declines, and } \\
\text { pain response (decline) }\end{array}$ & Docetaxel & $\begin{array}{c}\text { Reduced }(\geq 50 \% \text { in } \\
46 \%) \\
\end{array}$ \\
\hline Eribulin & $\begin{array}{l}\text { Bono et al. [65] } \\
\text { Phase II, } 108 \text { pts }\end{array}$ & PSA response rate & $\begin{array}{l}\text { Baseline (stratified by } \\
\text { prior taxane } \\
\text { exposure) }\end{array}$ & Reduced \\
\hline PROSTVAC-VF & $\begin{array}{l}\text { Kantoff et al. [72] } \\
\text { Phase II; } 125 \text { pts }\end{array}$ & $\begin{array}{l}44 \% \text { reduction in the death rate and an } \\
8.5 \text {-month improvement in median OS }\end{array}$ & $\begin{array}{l}\text { Control empty } \\
\text { vectors plus saline } \\
\text { injections }\end{array}$ & NA \\
\hline $\begin{array}{l}\text { Atrasentan (plus } \\
\text { Docetaxel) }\end{array}$ & $\begin{array}{l}\text { Carducci et al. [75] } \\
\text { Phase III; } 809 \text { pts }\end{array}$ & $\begin{array}{l}\text { Alkaline phosphatase and PSA levels were } \\
\text { significantly lower in the treatment arm }\end{array}$ & $\begin{array}{c}\text { Docetaxel and } \\
\text { placebo }\end{array}$ & Reduced \\
\hline $\begin{array}{l}\text { Bevacizumab (plus } \\
\text { Docetaxel) }\end{array}$ & $\begin{array}{c}\text { Kelly et al. [76] } \\
\text { Phase III; } 1050 \text { pts }\end{array}$ & $\begin{array}{l}\text { Improvement in PFS, measurable disease } \\
\text { response, and posttherapy PSA decline }\end{array}$ & Placebo & $\begin{array}{c}\text { Reduced }(\geq 50 \% \text { in } \\
69.5 \%) \\
\end{array}$ \\
\hline Ipilimumab & $\begin{array}{c}\text { NCT01057810 } \\
\text { [77] Phase III } \\
\text { ongoing } \\
\end{array}$ & NA & Placebo & NA \\
\hline Sunitinib & $\begin{array}{c}\text { Sonpavde et al. } \\
\text { [78] Phase II; } 36 \text { pts }\end{array}$ & PFS, PSA decline, pain control & NA & $\begin{array}{c}\text { Reduced }(\geq 50 \% \text { in } \\
12,1 \%) \\
\end{array}$ \\
\hline
\end{tabular}

${ }^{*}$ PFS: progression free survival; ${ }^{+}$OS: overall survival; ${ }^{\#}$ RR: response rate; pts: patients; NA: not available.

Tyrosine kinase inhibitors (TKIs) are important new class of target therapy that interfere with specific cell signaling pathways and thus allow target specific therapy for selected malignancies. Sorafenib and sunitinib have been tested in prostate cancer in phase I and II trials.

In the first stage of a phase II trial with sorafenib [92] 22 metastatic CRPC were enrolled. Most of the patients (59\%) had received prior therapy with docetaxel or mitoxantrone. Sorafenib therapy failed to show $>50 \%$ PSA reduction [18]. A second stage of the trial was conducted with 24 more patients [93]. Of the 24 patients, 21 had previous chemotherapy with docetaxel. All patients had bony metastases, either alone (in 11) or with soft-tissue disease (in 13). One patient had a partial response; 10 patients had stable disease (median duration 
18 weeks, range 15-48). At a median potential followup of 27.2 months, the median progression-free survival was 3.7 months and the median overall survival was 18.0 months. For the whole trial of 46 patients the median survival was 18.3 months. The authors concluded that sorafenib has moderate activity as a second-line treatment for metastatic castration-resistant prostate cancer in this trial population $[21,94]$.

Another phase II study [77] included 57 chemotherapy naïve CRPC patients. Fifty-five patients were evaluable. Two of these patients had $>50 \%$ PSA reduction and 15 patients had stable disease. Analysis of the results from a third phase II trial suggests that sorafenib therapy could affect PSA production or secretion regardless of its antitumor activity $[21,95]$.

A phase I/II trial of sunitinib in combination with docetaxel and prednisone showed a PSA response in $56 \%$ of patients, a median time to PSA progression of 42.1 weeks, and a partial response of measurable disease in 39\% patients [96].

Sunitinib was also tested in CRPC naïve and docetaxel refractory patients in other phase II trials [94, 95]. A phase III trial comparing sunitinib plus prednisone versus prednisone alone, in patients with docetaxel refractory metastatic CRPC, is ongoing. Overall survival is the primary endpoint of this study [18].

Cabozantinib is an inhibitor of MET and VEGFR2 [70]. Both the MET and VEGF-type 2 receptor signaling pathways appear to play important roles in the function of osteoblasts and osteoclasts. MET signaling promotes tumor growth, invasion, and metastasis. Results from cabozantinib trial were presented at ASCO Meeting, 2011. The authors concluded that cabozantinib showed clinical activity regardless of prior docetaxel in metastatic CRPC patients, particularly in patients with bone disease, in addition to improvements in hemoglobin and tumor regression.

ARQ-197 is an oral, selective, nonadenosine triphosphate competitive c-MET inhibitor [97]. Results from this clinical trial showed that ARQ 197 safely inhibited intratumoral c-MET signaling. Further clinical evaluation focusing on combination approaches is ongoing. Based on the first reports promising developments are expected.

There are also other potential targets, such as IGF-1R signaling, vitamin D receptor, PTEN, and phosphoinositide 3-kinase signaling; those are quite promising and could lead us to new treatment options [3].

Table 1 summarizes the main studies and the therapeutic impact of new drugs in CRPC treatment.

\section{Conclusions}

Androgen-deprivation therapy is generally the initial treatment for men with advanced prostate cancer. Different approaches include orchiectomy, LHRH agonist, or a combination of an LHRH agonist plus an antiandrogen (complete androgen blockade). Although patients have high response rates to the initial hormone therapy, nearly all of them eventually develop progressive, metastatic castrate-resistant, disease. In these patients other approaches are needed.
We know now that many of these CRPC tumors remain androgen dependent or AR stimulation dependent. Therefore it is possible that these patients benefit from sequential hormonotherapy (e.g., abiraterone acetate) as well as other new chemotherapy agents or biological approaches.

Individual target therapy is not yet available at this time, but remains a goal.

Current knowledge about the resistance mechanisms in castration-resistant prostate cancer has lead to new experiments and has identified possible new therapeutic targets. Promising results have already been presented in a broader spectrum of options. However, the survival benefit of these drugs in CRPC is still modest and some of the previous therapeutic options are not yet safe outside clinical trials. Therefore, well design and with potential clinical impact phase III trials are warranted, to coroborate the preliminary results and to answer unmet needs in CRPC.

\section{Acknowledgments}

T. Amaral works as a medical consultant for INFARMEDAutoridade Nacional do Medicamento e produtos de Saúde., I.P., National Authority of Medicines and Health Products, I.P. L. Costa has received honoraria and research grants from Novartis and Amgen and has received speaker fees from Novartis and Amgen. The other authors have no disclosures to report.

\section{References}

[1] N. Howlader, A. M. Noone, M. Krapcho et al., SEER Cancer Statistics Review, 1975-2008, National Cancer Institute, Bethesda, Md, USA, 2011, based on November 2010 SEER data submission, posted to the SEER web site, http://seer .cancer.gov/csr/1975_2008/.

[2] R. B. Marques, N. F. Dits, S. Erkens-Schulze, W. M. Weerden, and G. Jenster, "Bypass mechanisms of the androgen receptor pathway in therapy-resistant prostate cancer cell models," PLoS ONE, vol. 5, no. 10, Article ID e13500, 2010.

[3] G. Attard, D. Sarker, A. Reid, R. Molife, C. Parker, and J. S. De Bono, "Improving the outcome of patients with castrationresistant prostate cancer through rational drug development," British Journal of Cancer, vol. 95, no. 7, pp. 767-774, 2006.

[4] W. P. Harris, E. A. Mostaghel, P. S. Nelson, and B. Montgomery, "Androgen deprivation therapy: progress in understanding mechanisms of resistance and optimizing androgen depletion," Nature Clinical Practice Urology, vol. 6, no. 2, pp. 76-85, 2009.

[5] R. M. Attar, C. H. Takimoto, and M. M. Gottardis, "Castration-resistant prostate cancer: locking up the molecular escape routes," Clinical Cancer Research, vol. 15, no. 10, pp. 3251-3255, 2009.

[6] S. Sun, C. C. T. Sprenger, R. L. Vessella et al., "Castration resistance in human prostate cancer is conferred by a frequently occurring androgen receptor splice variant," Journal of Clinical Investigation, vol. 120, no. 8, pp. 2715-2730, 2010.

[7] P. A. Watson, Y. F. Chen, M. D. Balbas et al., "Constitutively active androgen receptor splice variants expressed in castration-resistant prostate cancer require full-length androgen receptor," Proceedings of the National Academy of Sciences 
of the United States of America, vol. 107, no. 39, pp. 16759$16765,2010$.

[8] C. J. Paller and E. S. Antonarakis, "Cabazitaxel: a novel secondline treatment for metastatic castration-resistant prostate cancer," Drug Design, Development and Therapy, no. 5, pp. 117-124, 2011.

[9] J. E. Ang, D. Olmos, and J. S. De Bono, "CYP17 blockade by abiraterone: further evidence for frequent continued hormone-dependence in castration-resistant prostate cancer," British Journal of Cancer, vol. 100, no. 5, pp. 671-675, 2009.

[10] S. S. Dutt and A. C. Gao, "Molecular mechanisms of castration-resistant prostate cancer progression," Future Oncology, vol. 5, no. 9, pp. 1403-1413, 2009.

[11] E. D. Crawford, M. A. Eisenberger, D. G. McLeod et al., "A controlled trial of leuprolide with and without flutamide in prostatic carcinoma," New England Journal of Medicine, vol. 321, no. 7, pp. 419-424, 1989.

[12] M. A. Eisenberger, B. A. Blumenstein, E. D. Crawford et al., "Bilateral orchiectomy with or without flutamide for metastatic prostate cancer," New England Journal of Medicine, vol. 339, no. 15, pp. 1036-1042, 1998.

[13] I. F. Tannock, R. De Wit, W. R. Berry et al., "Docetaxel plus prednisone or mitoxantrone plus prednisone for advanced prostate cancer," New England Journal of Medicine, vol. 351, no. 15, pp. 1502-1512, 2004.

[14] S. K. Pal, P. Twardowski, and O. Sartor, "Critical appraisal of cabazitaxel in the management of advanced prostate cancer," Clinical Interventions in Aging, vol. 5, pp. 395-402, 2010.

[15] P. W. Kantoff, C. S. Higano, N. D. Shore et al., "Sipuleucel-T immunotherapy for castration-resistant prostate cancer," New England Journal of Medicine, vol. 363, no. 5, pp. 411-422, 2010.

[16] E. J. Small, S. Halabi, N. A. Dawson et al., "Antiandrogen withdrawal alone or in combination with ketoconazole in androgen-independent prostate cancer patients: a phase III trial (CALGB 9583)," Journal of Clinical Oncology, vol. 22, no. 6, pp. 1025-1033, 2004.

[17] D. R. Berthold, C. N. Sternberg, and I. F. Tannock, "Management of advanced prostate cancer after first-line chemotherapy," Journal of Clinical Oncology, vol. 23, no. 32, pp. 82478252, 2005.

[18] S. J. Kim and S. I. Kim, "Current treatment strategies for castration-resistant prostate cancer," Korean Journal of Urology, vol. 52, no. 3, pp. 157-165, 2011.

[19] H. Suzuki, K. Okihara, H. Miyake et al., "Alternative nonsteroidal antiandrogen therapy for advanced prostate cancer that relapsed after initial maximum androgen blockade," Journal of Urology, vol. 180, no. 3, pp. 921-927, 2008.

[20] W. Kassouf, S. Tanguay, and A. G. Aprikian, "Nilutamide as second line hormone therapy for prostate cancer after androgen ablation fails," Journal of Urology, vol. 169, no. 5, pp. 1742-1744, 2003.

[21] R. Joyce, M. A. Fenton, P. Rode et al., "High dose bicalutamide for androgen independent prostate cancer: effect of prior hormonal therapy," Journal of Urology, vol. 159, no. 1, pp. 149153,1998

[22] O. Kucuk, E. Fisher, C. M. Moinpour et al., "Phase II trial of bicalutamide in patients with advanced prostate cancer in whom conventional hormonal therapy failed: a Southwest Oncology Group study (SWOG 9235)," Urology, vol. 58, no. 1, pp. 53-58, 2001.

[23] M. Lodde, L. Lacombe, and Y. Fradet, "Salvage therapy with bicalutamide $150 \mathrm{mg}$ in nonmetastatic castration-resistant prostate cancer," Urology, vol. 76, no. 5, pp. 1189-1193, 2010.
[24] G. Sonpavde, T. E. Hutson, and W. R. Berry, "Hormone refractory prostate cancer: management and advances," Cancer Treatment Reviews, vol. 32, no. 2, pp. 90-100, 2006.

[25] D. C. Smith, B. G. Redman, L. E. Flaherty, L. LI, M. Strawderman, and K. J. Pienta, "A Phase II trial of oral diethylstilbesterol as a second-line hormonal agent in advanced prostate cancer," Urology, vol. 52, no. 2, pp. 257-260, 1998.

[26] J. S. De Bono, C. J. Logothetis, A. Molina et al., "Abiraterone and increased survival in metastatic prostate cancer," New England Journal of Medicine, vol. 364, no. 21, pp. 1995-2005, 2011.

[27] G. A. Potter, S. Elaine Barrie, M. Jarman, and M. G. Rowlands, "Novel steroidal inhibitors of human cytochrome $\mathrm{P} 40_{17 \alpha}$ (17 $\alpha$-hydroxylase- $\mathrm{C}_{17,20}$-lyase): potential agents for the treatment of prostatic cancer," Journal of Medicinal Chemistry, vol. 38, no. 13, pp. 2463-2471, 1995.

[28] G. Attard, A. S. Belldegrun, and J. S. De Bono, "Selective blockade of androgenic steroid synthesis by novel lyase inhibitors as a therapeutic strategy for treating metastatic prostate cancer," British Journal of Urology International, vol. 96, no. 9, pp. 1241-1246, 2005.

[29] S. E. Barrie, B. P. Haynes, G. A. Potter et al., "Biochemistry and pharmacokinetics of potent non-steroidal cytochrome $\mathrm{P} 40_{17 \alpha}$ inhibitors," Journal of Steroid Biochemistry and Molecular Biology, vol. 60, no. 5-6, pp. 347-351, 1997.

[30] M. Jarman, S. Elaine Barrie, and J. M. Liera, "The 16,17double bond is needed for irreversible inhibition of human cytochrome $\mathrm{P}^{4} 50_{17 \alpha}$ by abiraterone (17-(3-Pyridyl)androsta5,16-dien-3 $\beta$-ol) and related steroidal inhibitors," Journal of Medicinal Chemistry, vol. 41, no. 27, pp. 5375-5381, 1998.

[31] P. Vishnu and W. W. Tan, "Update on options for treatment of metastatic castration-resistant prostate cancer," OncoTargets and Therapy, vol. 3, pp. 39-51, 2010.

[32] A. O. Sartor, "Progression of metastatic castrate-resistant prostate cancer: impact of therapeutic intervention in the post-docetaxel space," Journal of Hematology and Oncology, vol. 4, article 18, 2011.

[33] D. Bianchini, A. Zivi, S. Sandhu, and J. S. de Bono, "Horizon scanning for novel therapeutics for the treatment of prostate cancer," Annals of Oncology, vol. 21, supplement 7, pp. vii43vii55, 2010.

[34] H. I. Scher, A. Anand, D. Rathkopf et al., "Antitumour activity of MDV3100 in castration-resistant prostate cancer: a phase 12 study," The Lancet, vol. 375, no. 9724, pp. 1437-1446, 2010.

[35] L. Zarour and J. Alumkal, "Emerging therapies in castrateresistant prostate cancer," Current Urology Reports, vol. 11, no. 3, pp. 152-158, 2010.

[36] F. Saad, D. M. Gleason, R. Murray et al., "A randomized, placebo-controlled trial of zoledronic acid in patients with hormone-refractory metastatic prostate carcinoma," Journal of the National Cancer Institute, vol. 94, no. 19, pp. 1458-1468, 2002.

[37] K. P. Weinfurt, K. J. Anstrom, L. D. Castel, K. A. Schulman, and F. Saad, "Effect of zoledronic acid on pain associated with bone metastasis in patients with prostate cancer," Annals of Oncology, vol. 17, no. 6, pp. 986-989, 2006.

[38] F. Saad, D. M. Gleason, R. Murray et al., "Long-term efficacy of zoledronic acid for the prevention of skeletal complications in patients with metastatic hormone-refractory prostate cancer," Journal of the National Cancer Institute, vol. 96, no. 11, pp. 879-882, 2004.

[39] T. H. Diamond, J. Winters, A. Smith et al., "The antiosteoporotic efficacy of intravenous pamidronate in men with 
prostate carcinoma receiving combined androgen blockade: a double blind, randomized, placebo-controlled crossover study," Cancer, vol. 92, no. 6, pp. 1444-1450, 2001.

[40] R. S. Israeli, S. J. Rosenberg, D. R. Saltzstein et al., "The effect of zoledronic acid on bone mineral density in patients undergoing androgen deprivation therapy," Clinical Genitourinary Cancer, vol. 5, no. 4, pp. 271-277, 2007.

[41] M. R. Smith, J. Eastham, D. M. Gleason, D. Shasha, S. Tchekmedyian, and N. Zinner, "Randomized controlled trial of zoledronic acid to prevent bone loss in men receiving androgen deprivation therapy for nonmetastatic prostate cancer," Journal of Urology, vol. 169, no. 6, pp. 2008-2012, 2003.

[42] K. Fizazi, M. Carducci, M. Smith et al., "Denosumab versus zoledronic acid for treatment of bone metastases in men with castration-resistant prostate cancer: a randomised, doubleblind study," The Lancet, vol. 377, no. 9768, pp. 813-822, 2011.

[43] E. Steenland, J. Leer, H. Van Houwelingen et al., "The effect of a single fraction compared to multiple fractions on painful bone metastases: a global analysis of the Dutch Bone Metastasis study," Radiotherapy and Oncology, vol. 52, no. 2, pp. 101-109, 1999.

[44] Y. M. Van Der Linden, J. J. Lok, E. Steenland et al., "Single fraction radiotherapy is efficacious: a further analysis of the Dutch Bone Metastasis Study controlling for the influence of retreatment," International Journal of Radiation Oncology Biology Physics, vol. 59, no. 2, pp. 528-537, 2004.

[45] W. F. Harstell, C. B. Scott, D. W. Bruner et al., "Randomized trial of short-versus long-course radiotherapy for palliation of painful bone metastases," Journal of the National Cancer Institute, vol. 97, no. 11, pp. 798-804, 2005.

[46] E. Chow, K. Harris, G. Fan, M. Tsao, and W. M. Sze, "Palliative radiotherapy trials for bone metastases: a systematic review," Journal of Clinical Oncology, vol. 25, no. 11, pp. 1423-1436, 2007.

[47] O. M. Salazar, T. Sandhu, N. W. Da Motta et al., "Fractionated half-body irradiation (HBI) for the rapid palliation of widespread, symptomatic, metastatic bone disease: a randomized Phase III trial of the International Atomic Energy Agency (IAEA)," International Journal of Radiation Oncology Biology Physics, vol. 50, no. 3, pp. 765-775, 2001.

[48] D. P. Dearnaley, R. J. Bayly, R. P. A'Hern, J. Gadd, M. M. Zivanovic, and V. J. Lewington, "Palliation of bone metastases in prostate cancer. Hemibody irradiation or strontium-89?" Clinical Oncology, vol. 4, no. 2, pp. 101-107, 1992.

[49] V. J. Lewington, A. J. McEwan, D. M. Ackery et al., "A prospective, randomised double-blind crossover study to examine the efficacy of strontium-89 in pain palliation in patients with advanced prostate cancer metastatic to bone," European Journal of Cancer, vol. 27, no. 8, pp. 954-958, 1991.

[50] K. Buchali, H. J. Correns, M. Schuerer, D. Schnorr, H. Lips, and K. Sydow, "Results of a double blind study of 89strontium therapy of skeletal metastases of prostatic carcinoma," European Journal of Nuclear Medicine, vol. 14, no. 7-8, pp. 349-351, 1988.

[51] A. T. Porter, A. J. B. McEwan, J. E. Powe et al., "Results of a randomized Phase-III trial to evaluate the efficacy of strontium-89 adjuvant to local field external beam irradiation in the management of endocrine resistant metastatic prostate cancer," International Journal of Radiation Oncology Biology Physics, vol. 25, no. 5, pp. 805-813, 1993.

[52] P. M. Quilty, D. Kirk, J. J. Bolger et al., "A comparison of the palliative effects of strontium- 89 and external beam radiotherapy in metastatic prostate cancer," Radiotherapy and Oncology, vol. 31, no. 1, pp. 33-40, 1994.

[53] G. O. N. Oosterhof, J. T. Roberts, T. M. De Reijke et al., "Strontium(89) chloride versus palliative local field radiotherapy in patients with hormonal escaped prostate cancer: a phase III study of the European Organisation for Research and Treatment of Cancer, Genitourinary Group," European Urology, vol. 44, no. 5, pp. 519-526, 2003.

[54] A. N. Serafini, S. J. Houston, I. Resche et al., "Palliation of pain associated with metastatic bone cancer using samarium-153 lexidronam: a double-blind placebo-controlled clinical trial," Journal of Clinical Oncology, vol. 16, no. 4, pp. 1574-1581, 1998.

[55] O. Sartor, R. H. Reid, P. J. Hoskin et al., "Samarium-153lexidronam complex for treatment of painful bone metastases in hormone-refractory prostate cancer," Urology, vol. 63, no. 5, pp. 940-945, 2004.

[56] C. Parker, D. Heinrich, J. M. O’Sullivan et al., "Overall survival benefit of radium-223 chloride (Alpharadin) in the treatment of patients with symptomatic bone metastases in castration-resistant prostate cancer: a phase III randomized trial (ALSYMPCA)," European Journal of Cancer, vol. 47, supplement 2, abstract 1LBA, p. 3, 2011.

[57] D. P. Petrylak, C. M. Tangen, M. H. A. Hussain et al., "Docetaxel and estramustine compared with mitoxantrone and prednisone for advanced refractory prostate cancer," New England Journal of Medicine, vol. 351, no. 15, pp. 1513-1520, 2004.

[58] M. D. Galsky and N. J. Vogelzang, "Docetaxel-based combination therapy for castration-resistant prostate cancer," Annals of Oncology, vol. 21, no. 11, pp. 2135-2144, 2010.

[59] M. D. Galsky, E. J. Small, W. K. Oh et al., "Multi-institutional randomized phase II trial of the epothilone B analog ixabepilone (BMS-247550) with or without estramustine phosphate in patients with progressive castrate metastatic prostate cancer," Journal of Clinical Oncology, vol. 23, no. 7, pp. 1439-1446, 2005.

[60] M. Hussain, C. M. Tangen, P. N. Lara et al., "Ixabepilone (epothilone B analogue BMS-247550) is active in chemotherapy-naive patients with hormone-refractory prostate cancer: a Southwest Oncology Group Trial S0111," Journal of Clinical Oncology, vol. 23, no. 34, pp. 8724-8729, 2005.

[61] J. E. Rosenberg, W. K. Kelly, M. D. Michaelson et al., "A randomized phase II study of ixabepilone (Ix) or mitoxantrone and prednisone (MP) in patients with taxane (T)-resistant hormone refractory prostate cancer (HRPC)," Journal of Clinical Oncology, vol. 23, no. 16S, abstract \#5166, p. 4566, 2005.

[62] K. N. Chi, E. K. Beardsley, P. M. Venner et al., "A phase II study of patupilone in patients with metastatic hormone refractory prostate cancer (HRPC) who have progressed after docetaxel," Journal of Clinical Oncology, vol. 26, no. 15s, Abstract \#5166, 2008.

[63] E. K. Beardsley, F. Saad, and B. Eigl, "A phase II study of patupilone in patients (patients) with metastatic castrationresistant prostate cancer (CRPC) who have progressed after docetaxel," Journal of Clinical Oncology, vol. 27, no. 15s, abstract \#5139, 2009.

[64] J. E. Rosenberg, V. K. Weinberg, W. K. Kelly et al., "Activity of second-line chemotherapy in docetaxel-refractory hormonerefractory prostate cancer patients: randomized phase 2 study of ixabepilone or mitoxantrone and prednisone," Cancer, vol. 110, no. 3, pp. 556-563, 2007. 
[65] J. S. Bono, P. Maroto, E. Calvo et al., "Phase II study of eribulin mesylate (E7389) in patients (pts) with metastatic castrationresistant prostate cancer (CRPC) stratified by prior taxane therapy," Annals of Oncology, pp. mdr380v1-mdr380, 2011.

[66] J. S. De Bono, S. Oudard, M. Ozguroglu et al., "Prednisone plus cabazitaxel or mitoxantrone for metastatic castrationresistant prostate cancer progressing after docetaxel treatment: a randomised open-label trial," The Lancet, vol. 376, no. 9747, pp. 1147-1154, 2010.

[67] E. J. Small, P. F. Schellhammer, C. S. Higano et al., "Placebo-controlled phase III trial of immunologic therapy with Sipuleucel-T (APC8015) in patients with metastatic, asymptomatic hormone refractory prostate cancer," Journal of Clinical Oncology, vol. 24, no. 19, pp. 3089-3094, 2006.

[68] C. S. Higano, P. F. Schellhammer, E. J. Small et al., "Integrated data from 2 randomized, double-blind, placebocontrolled, phase 3 trials of active cellular immunotherapy with sipuleucel-T in advanced prostate cancer," Cancer, vol. 115, no. 16, pp. 3670-3679, 2009.

[69] E. J. Small, N. Sacks, J. Nemunaitis et al., "Granulocyte macrophage colony-stimulating factor-secreting allogeneic cellular immunotherapy for hormone-refractory prostate cancer," Clinical Cancer Research, vol. 13, no. 13, pp. 3883-3891, 2007.

[70] M. Hussain, M. R. Smith, C. Sweeney et al., "Cabozantinib (XL184) in metastatic castration-resistant prostate cancer (mCRPC): results from a phase II randomized discontinuation trial," Journal of Clinical Oncology, vol. 29, supplement, abstract 4516, 2011.

[71] E. Cha and L. Fong, "Therapeutic vaccines for prostate cancer," Current Opinion in Molecular Therapeutics, vol. 12, no. 1, pp. 77-85, 2010.

[72] P. W. Kantoff, T. J. Schuetz, B. A. Blumenstein et al., “Overall survival analysis of a phase II randomized controlled trial of a Poxviral-based PSA-targeted immunotherapy in metastatic castration-resistant prostate cancer," Journal of Clinical Oncology, vol. 28, no. 7, pp. 1099-1105, 2010.

[73] G. Sonpave, K. M. Slawin, D. M. Spencer, and J. M. Levitt, "Emerging vaccine therapy approaches for prostate cancer," Reviews in Urology, vol. 12, pp. 25-34, 2010.

[74] M. A. Carducci and A. Jimeno, "Targeting bone metastasis in prostate cancer with endothelin receptor antagonists," Clinical Cancer Research, vol. 12, no. 20, pp. 6296s-6300s, 2006.

[75] M. A. Carducci, F. Saad, P.-A. Abrahamsson et al., "A phase 3 randomized controlled trial of the efficacy and safety of atrasentan in men with metastatic hormone-refractory prostate cancer," Cancer, vol. 110, no. 9, pp. 1959-1966, 2007.

[76] W. K. Kelly, S. Halabi, M. A. Carducci et al., "A randomized, double-bind, placebo-controlled phase III trial comparing docetaxel, prednisone, and bevacizumab in men with metastatic castration-resistant prostate cancer (mCRPC): survival results of CALGB 90401," Journal of Clinical Oncology, vol. 28, no. 18s, abstract LBA4511, 2010.

[77] NCT01057810 Randomized, Double-Blind, Phase 3 Trial to Compare the Efficacy of Ipilumumab vs Placebo in Asymptomatic or Minimally Symptomatic Patients With Metastatic Chemotherapy-Naïve Castration Resistant Prostate Cancer.

[78] G. Sonpavde, P. O. Periman, D. Bernold et al., "Sunitinib malate for metastatic castration-resistant prostate cancer following docetaxel-based chemotherapy," Annals of Oncology, vol. 21, no. 2, pp. 319-324, 2010.

[79] M. A. Carducci, R. J. Padley, J. Breul et al., "Effect of endothelin-A receptor blockade with atrasentan on tumor progression in men with hormone-refractory prostate cancer: a randomized, phase II, placebo-controlled trial," Journal of Clinical Oncology, vol. 21, no. 4, pp. 679-689, 2003.

[80] Phase III Study of Docetaxel and Atrasentan Versus Docetaxel and Placebo for Patients With Advanced Hormone Refractory Prostate Cancer National Institutes of Health. Clinical Trials 2011, http://clinicaltrials.gov/ .

[81] N. D. James, A. Caty, H. Payne et al., "Final safety and efficacy analysis of the specific endothelin A receptor antagonist zibotentan (ZD4054) in patients with metastatic castrationresistant prostate cancer and bone metastases who were painfree or mildly symptomatic for pain: a double-blind, placebocontrolled, randomized Phase II trial," British Journal of Urology International, vol. 106, no. 7, pp. 966-973, 2010.

[82] A Phase III Trial of ZD4054 (Zibotentan) (Endothelin A Antagonist) in Non-metastatic Hormone Resistant Prostate Cancer (ENTHUSE M0) NCT00626548.

[83] A Phase III Trial of ZD4054 (Zibotentan) (Endothelin A Antagonist) and Docetaxel in Metastatic Hormone Resistant Prostate Cancer (ENTHUSE M1C) NCT00617669.

[84] W. L. Dahut, J. L. Gulley, P. M. Arlen et al., "Randomized phase II trial of docetaxel plus thalidomide in androgenindependent prostate cancer," Journal of Clinical Oncology, vol. 22, no. 13, pp. 2532-2539, 2004.

[85] G. Di Lorenzo, W. D. Figg, S. D. Fossa et al., "Combination of bevacizumab and docetaxel in docetaxel-pretreated hormonerefractory prostate cancer: a phase 2 study," European Urology, vol. 54, no. 5, pp. 1089-1096, 2008.

[86] J. Picus, S. Halabi, W. K. Kelly et al., "A phase 2 study of estramustine, docetaxel, and bevacizumab in men with castrate-resistant prostate cancer," Cancer, vol. 117, no. 3, pp. 526-533, 2011.

[87] Y. M. Ning, J. L. Gulley, P. M. Arlen et al., "Phase II trial of bevacizumab, thalidomide, docetaxel, and prednisone in patients with metastatic castration-resistant prostate cancer," Journal of Clinical Oncology, vol. 28, no. 12, pp. 2070-2076, 2010.

[88] National Institutes of Health Clinical Trials database, http:// clinicaltrials.gov/.

[89] E. J. Small, N. S. Tchekmedyian, B. I. Rini, L. Fong, I. Lowy, and J. P. Allison, "A pilot trial of CTLA-4 blockade with human anti-CTLA-4 in patients with hormone-refractory prostate cancer," Clinical Cancer Research, vol. 13, no. 6, pp. 1810-1815, 2007.

[90] L. Fong, S. S. Kwek, S. O’Brien et al., "Potentiating endogenous antitumor immunity to prostate cancer through combination immunotherapy with CTLA4 blockade and GM-CSF," Cancer Research, vol. 69, no. 2, pp. 609-615, 2009.

[91] NCT00861614 A Randomized, Double-Blind, Phase 3 Trial Comparing Ipilumumab vs. Placebo Following Radiotherapy in Subjects With Castration Resistant Prostate Cancer That Have Received Prior Treatment With Docetaxel.

[92] W. L. Dahut, C. Scripture, E. Posadas et al., "A phase II clinical trial of sorafenib in androgen-independent prostate cancer," Clinical Cancer Research, vol. 14, no. 1, pp. 209-214, 2008.

[93] J. B. Aragon-Ching, L. Jain, J. L. Gulley et al., "Final analysis of a phase II trial using sorafenib for metastaticcastrationresistant prostate cancer," British Journal of Urology International, vol. 103, no. 12, pp. 1636-1640, 2009.

[94] S. Steinbild, K. Mross, A. Frost et al., "A clinical phase II study with sorafenib in patients with progressive hormonerefractory prostate cancer: a study of the CESAR Central European Society for Anticancer Drug Research-EWIV," British Journal of Cancer, vol. 97, no. 11, pp. 1480-1485, 2007. 
[95] K. N. Chi, S. L. Ellard, S. J. Hotte et al., "A phase II study of sorafenib in patients with chemo-naive castration-resistant prostate cancer," Annals of Oncology, vol. 19, no. 4, pp. 746751, 2008.

[96] A. J. Zurita, G. Liu, T. Hutson et al., "Sunitinib in combination with docetaxel and prdnisone in patients (pts) with metastatic hormone-refrectory prostate cancer (mHRPC)," Journal of Clinical Oncology, vol. 27, no. 15s, abstract 5166, 2009.

[97] T. A. Yap, D. Olmos, A. T. Brunetto et al., "Phase I trial of a selective c-MET inhibitor ARQ 197 incorporating proof of mechanism pharmacodynamic studies," Journal of Clinical Oncology, vol. 29, no. 10, pp. 1271-1279, 2011. 


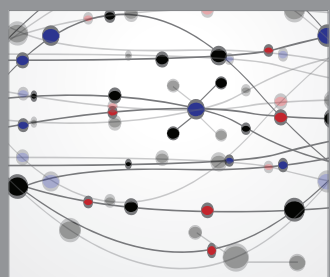

The Scientific World Journal
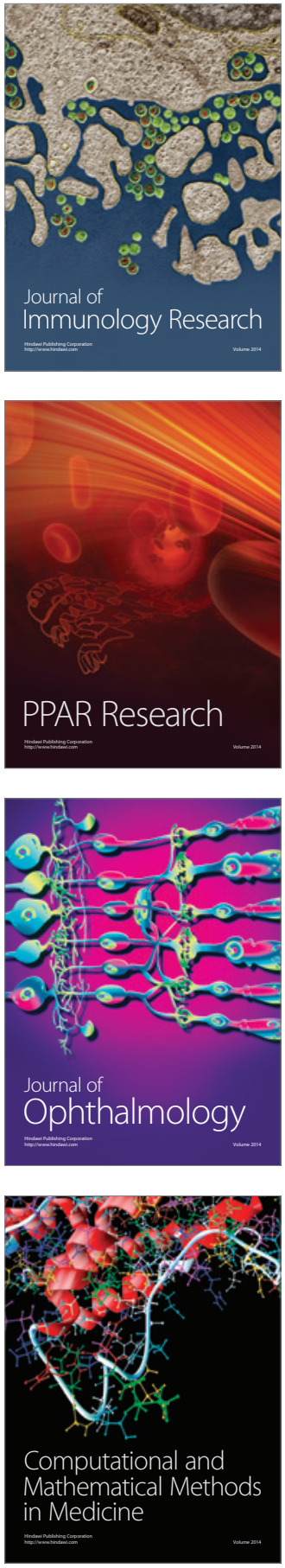

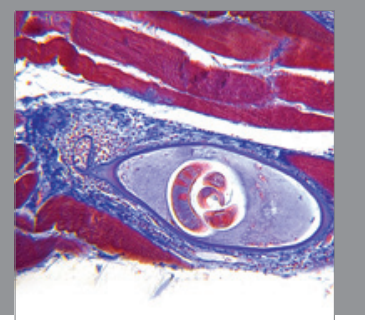

Gastroenterology

Research and Practice
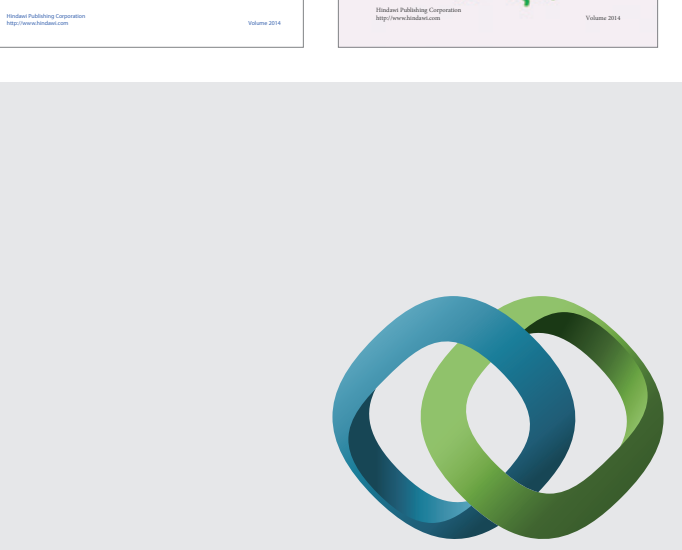

\section{Hindawi}

Submit your manuscripts at

http://www.hindawi.com
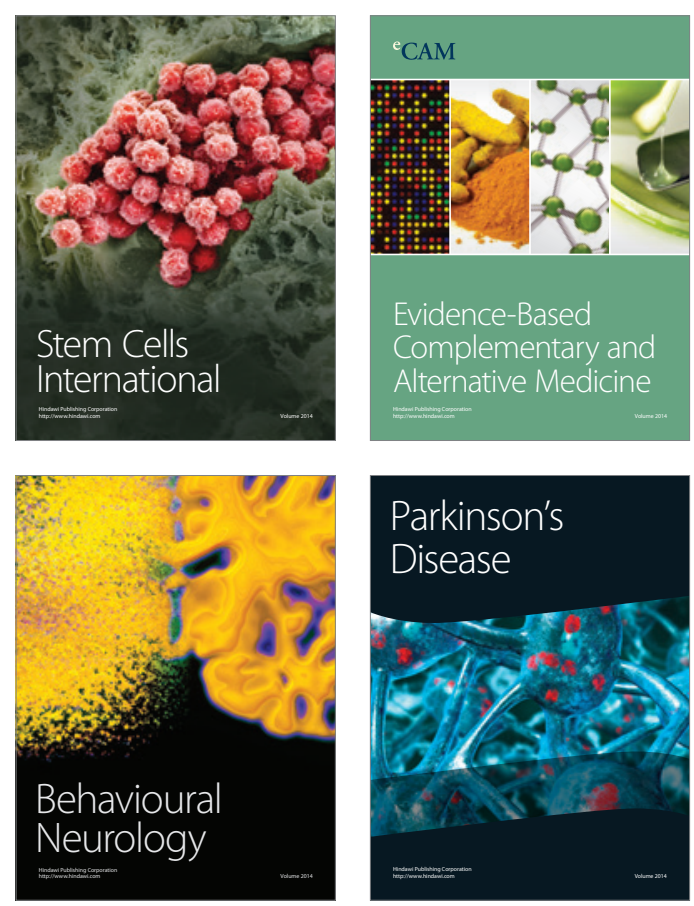

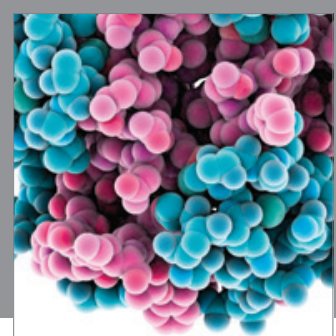

Journal of
Diabetes Research

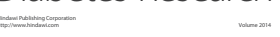

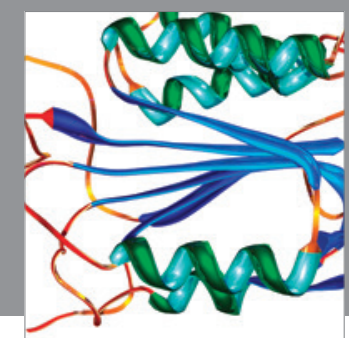

Disease Markers
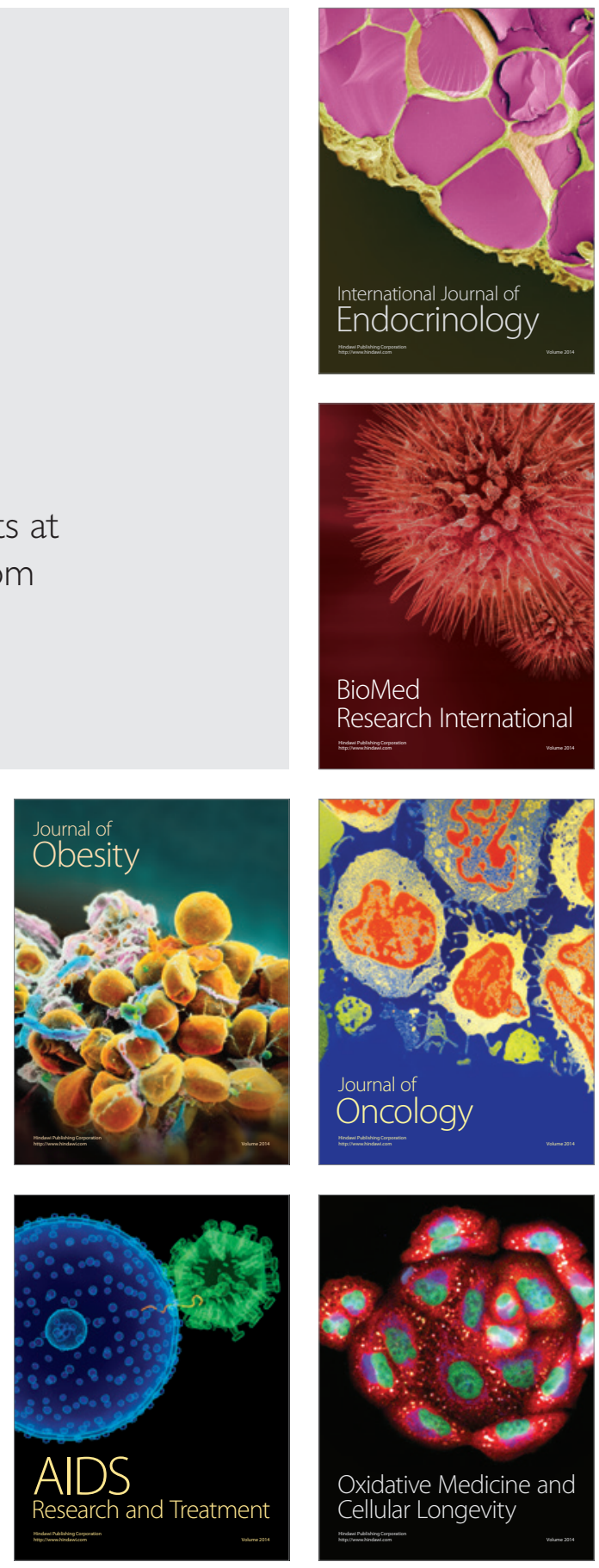